\title{
Long-term 24-hour Intraocular Pressure Control With Travoprost Monotherapy in Patients With Primary Open-angle Glaucoma
}

\author{
Ivano Riva, MD, ${ }^{*}$ Andreas Katsanos, MD, PhD, $\dagger$ Irene Floriani, PhD, $\dagger$ \\ Elena Biagioli, ScD, Anastasios G.P. Konstas, MD, PhD, $\S$ \\ Marco Centofanti, MD, PhD, $\|$ and Luciano Quaranta, MD, PhD*
}

\begin{abstract}
Purpose: The aim of the study was to evaluate the long-term 24hour intraocular pressure (IOP) efficacy of travoprost monotherapy in primary open-angle glaucoma patients.

Patients and Methods: A total of 36 previously untreated primary open-angle glaucoma patients were enrolled in this 5-year study. Patients underwent an untreated 24-hour IOP evaluation. Subsequently all patients were assigned to topical therapy with travoprost $0.004 \%$ eye-drops preserved with benzalkonium chloride (Travatan, Alcon Laboratories Inc., Fort Worth, TX) administered once in the evening (8:00 PM) in both eyes. All patients were then scheduled for a 24-hour IOP assessment approximately 12 months after the baseline visit. This schedule of follow-up was maintained for the whole duration of the trial. The predetermined range of target IOP reduction selected in this cohort of patients ranged between $20 \%$ and $30 \%$.
\end{abstract}

Results: A total of 34 patients completed all phases of the investigation. The mean survival time was $57.3 \pm 2.0$ months and the cumulative survival rate was $0.82 \pm 0.6$ at 60 months. Travoprost reduced the mean 24-hour IOP from $23.4 \pm 1.7 \mathrm{~mm} \mathrm{Hg}$ at baseline to $16.8 \pm 2.4 \mathrm{~mm} \mathrm{Hg}(28.4 \%), 16.8 \pm 2.5 \mathrm{~mm} \mathrm{Hg} \quad(28.1 \%)$, $16.8 \pm 2.4 \mathrm{~mm} \mathrm{Hg}(28.5 \%), 16.7 \pm 2.5 \mathrm{~mm} \mathrm{Hg}(28.6 \%)$, and $16.9 \pm 2.4 \mathrm{~mm} \mathrm{Hg}(27.8 \%)$, respectively at the end of the first, second, third, fourth, and fifth year follow-up. No drug-related serious adverse events were registered during the study.

Conclusions: The present study demonstrated the long-term 24hour efficacy of travoprost for the treatment of primary open-angle glaucoma.

Key Words: open-angle glaucoma, prostaglandin analogue, circadian intraocular pressure, travoprost

( J Glaucoma 2014;23:535-540)

Received for publication July 11, 2013; accepted March 14, 2014.

From the *Centre for the Study of Glaucoma, University of Brescia, Brescia; LLaboratory of Clinical Research, IRCCS, Istituto di Ricerche Farmacologiche Mario Negri, Milano; \#DSCMT, University of Tor Vergata, Rome, Italy; †Ophthalmology Department, University of Ioannina, Ioannina; and \$Glaucoma Unit, 1st University Department of Ophthalmology, AHEPA Hospital, Thessaloniki, Greece.

Disclosure: I.R.: Honoraria or travel reimbursement from Alcon, Allergan, MSD, Sooft; A.K.: Travel reimbursement from Alcon and MSD; A.G.P.K.: Consultant for Alcon, Allergan, MSD and Nicox; L.Q.: Honoraria or travel reimbursement from Alcon, Allergan, MSD, Thea-Farmila, and Bausch \& Lomb. I.F., E.B., M.C. declares no conflict of interest.

Reprints: Luciano Quaranta, MD, PhD, A.O. Spedali Civili di Brescia, Unità di Oculistica, Piazzale Spedali Civili, 1, Brescia 25123, Italy (e-mail: quaranta@med.unibs.it).

Copyright (C) 2014 by Lippincott Williams \& Wilkins

DOI: 10.1097/IJG.0000000000000073
Deduction of intraocular pressure (IOP) is the only curRently available, evidence-based management strategy in patients affected with primary open-angle glaucoma (POAG). Most POAG patients will require lifelong medical therapy to avoid visual loss. The decision to select medical therapy options relies primarily on the efficacy of the available medications in various therapeutic trials. Sadly, most published studies only evaluate the short-term, daytime efficacy of medical therapy.

Prostaglandin analogues have become a popular firstline therapy option for lowering IOP in POAG owing to their superior 24 -hour efficacy, ${ }^{1-6}$ convenient once-a-day administration, ${ }^{5}$ and favorable systemic safety profile. ${ }^{7}$ Travoprost is a synthetic prostaglandin F $2 \alpha$ analogue that exerts its IOP-lowering effect through the prostaglandin FP receptors situated at the ciliary muscle ${ }^{8}$ and the trabecular meshwork. ${ }^{9}$ Travoprost is increasingly becoming a popular first-line monotherapy option for POAG patients ${ }^{10}$ as there is cumulative evidence suggesting good quality of shortterm 24-hour IOP control with low fluctuation, especially with evening administration. ${ }^{11-13}$ However, although several controlled studies have demonstrated the daytime short-term efficacy of travoprost monotherapy, ${ }^{14-16}$ little is currently known about its long-term efficacy.

As POAG is a 24-hour, lifelong disease, an ideal antiglaucoma medication should be successful in reducing IOP during day and night. ${ }^{4,17}$ Importantly, 24-hour studies have confirmed that 24-hour IOP monitoring can significantly modify individualized glaucoma care in many glaucoma patients. ${ }^{18,19}$ A few 24-hour studies have investigated travoprost efficacy over a period of up to 4 months, ${ }^{11-13,20}$ but to date no evidence is available for the long-term 24-hour efficacy of travoprost monotherapy in glaucoma.

Therefore, the primary aim of this study was the evaluation of the long-term 24-hour IOP efficacy obtained by travoprost monotherapy, used as a first-line therapy during a 5-year follow-up period. A secondary aim was to investigate the survival rate without progression of a POAG cohort treated with travoprost monotherapy.

\section{MATERIALS AND METHODS}

This was a prospective, open label, single-arm study carried out at the Glaucoma Service of the Department of Ophthalmology of the University of Brescia, Italy. The research protocol adhered to the tenets of the Declaration of Helsinki and was approved by the Institutional Review Board of the University of Brescia, Italy. Enrolled patients provided a written informed consent to participate in the trial before any study-related activities were carried out. 


\section{Participants}

This study enrolled newly diagnosed, previously untreated POAG patients who exhibited characteristic glaucomatous disc damage and visual field loss between January and November 2005. Eligibility criteria were: age above 45 years, no previous ocular surgery other than uncomplicated phacoemulsification cataract surgery performed at least 6 months before entering the study, openangle by gonioscopy (grades III and IV according to the Shaffer classification), untreated IOP between 21 and $35 \mathrm{~mm} \mathrm{Hg}$ at 10:00 $\mathrm{Am} \pm 1$ hour verified by 2 separate measurements (enrollment IOP).

Exclusion criteria for ophthalmic conditions were: any type of glaucoma other than POAG; corneal or other anatomic conditions making applanation tonometry unreliable; central corneal thickness $\leq 500 \mu \mathrm{m}$ or $\geq 600 \mu \mathrm{m}$; signs or history of macular edema, herpetic, or other ocular inflammatory disease; history of allergy or adverse event related to the study medication; history or suspicion of poor adherence to medical therapy; best-corrected visual acuity $<0.4$ (Snellen); cup-to-disc ratio $>0.7$; mean deviation (MD) worse than $-15 \mathrm{~dB}$ in Humphrey 24-2 SITA standard perimetry (Humphrey Visual Field Analyzer; Carl Zeiss Meditec Inc., Dublin, CA); or the possibility of significant visual deterioration and optic nerve damage due to participation to the study according to the principal investigator's judgment. Patients were also excluded if they were unable to understand the study procedures, give informed consent, or were using systemic corticosteroids.

\section{Assessments}

During an initial eligibility visit, all qualified patients underwent a detailed ophthalmic examination and their ocular and systemic clinical data were recorded. Study participants were admitted at the University Ophthalmology Clinic of Brescia, Italy, for an untreated 24-hour IOP evaluation (baseline visit) with Goldmann tonometry. The IOP was recorded at 10:00 $\mathrm{AM}, 2: 00 \mathrm{PM}, 6: 00 \mathrm{PM}, 10: 00 \mathrm{PM}$, 2:00 AM, 6:00 AM, and 10:00 Aм $( \pm 1 \mathrm{~h})$. The day before the 24-hour IOP assessment, a reliable 24-2 SITA standard visual field test was performed (Humphrey Visual Field Analyzer; Carl Zeiss Meditec Inc.).

Subsequently all study patients were assigned to topical therapy with travoprost $0.004 \%$ eye-drops preserved with benzalkonium chloride (Travatan, Alcon Laboratories Inc.) administered once in the evening (8:00 PM) in both eyes. To ensure that the target IOP was reached, according to the principal investigator's judgment, a safety visit was performed approximately 4 weeks after treatment initiation. The predetermined range of target IOP reduction selected in this cohort with travoprost monotherapy ranged between $20 \%$ and $30 \%$. After this visit, all patients were scheduled for a visit approximately 6 months after the baseline visit at 10:00 AM \pm 1 hour, as well as a 24-hour IOP assessment approximately 12 months after the baseline visit. This schedule of follow-up was maintained for the whole duration of the trial. A comprehensive clinical examination was performed at each visit. Enrolled patients continued on travoprost monotherapy as long as their target IOP was successfully maintained. Calibrated Goldmann tonometers were used throughout the duration of the trial by a clinician masked to the previous baseline or treated IOP data.

\section{Statistics}

The primary endpoint of the study was the mean 24-hour IOP measured at annual intervals. Only 1 eye per patient was included in the analysis. The mean values for 24-hour IOP, daytime IOP, and nocturnal IOP were obtained from every 24-hour IOP curve. Areas under the curve (AUCs) were calculated for each variable, using a trapezoidal rule. The trend over time for each variable was evaluated by means of an analysis of variance model for repeated measures, whereas a paired $t$ test was used for comparison of variables at each time-point with baseline values. A Bonferroni approach was adopted to allow for multiple tests: considering an $\alpha$ level of 0.05 , statistical significance was set to 0.01 , calculating as 0.05 divided for 5 comparisons. In these analyses, the approach of the last value carried forward was applied for patients who did not complete the study.

Failure was defined as withdrawal of a patient from the study, due to either failure to reach the target IOP set upon enrollment or when reliable evidence of progression existed, necessitating the introduction of adjunctive medical therapy. The percentage of patients meeting target IOP at every annual time-point was calculated. The Kaplan-Meier survival method was used to describe the cumulative incidence of travoprost monotherapy failure throughout the 5 years of the study. The mean survival time and cumulative survival rate at 60 months were computed. An intent-totreat approach was applied for the analysis.

Univariate Cox regression analysis was performed to evaluate age, MD, pattern standard deviation, baseline 24hour IOP, treated 24-hour IOP fluctuation, and treated 24hour peak IOP as risk factors for progression/failure. Treated 24-hour IOP fluctuation was defined as the SD of the IOPs recorded during the treatment phase of the study and reported in $\mathrm{mm} \mathrm{Hg}$. Treated IOP peak was defined as the mean of peak IOPs (ie, highest point in the range of the 24-hour pressure curve) computed for each 24-hour assessment during the treatment phase of the study. Descriptive statistics were calculated for every variable and variables were compared between nonfailure and failure group of patients using an independent $t$ test. Hazard ratios (HR) for failure were reported for each putative factor in the univariate analysis.

\section{RESULTS}

Thirty-six POAG patients were enrolled in this 5-year study. Thirty-four patients completed all phases of the investigation, whereas 2 patients were lost to follow-up, both at approximately 48 months. Six patients were withdrawn from the study because their target IOP could not be reached at some stage, or because of reliable evidence of progression (Fig. 1). Respectively 97.2\%, 97.2\%, 94.4\%, $94.4 \%$, and $94.4 \%$ of patients met their target IOP at first, second, third, fourth, and fifth year of follow-up. For the whole study population, the mean survival time was $57.3 \pm 2.0$ months and the cumulative survival rate was $0.82 \pm 0.6$ at 60 months. Table 1 shows the general features of the patients included.

Travoprost reduced the mean 24-hour IOP from $23.4 \pm 1.7 \mathrm{~mm} \mathrm{Hg}$ at baseline to $16.8 \pm 2.4 \mathrm{~mm} \mathrm{Hg}$ $(28.4 \%), 16.8 \pm 2.5 \mathrm{~mm} \mathrm{Hg}(28.1 \%), 16.8 \pm 2.4 \mathrm{~mm} \mathrm{Hg}$ $(28.5 \%), 16.7 \pm 2.5 \mathrm{~mm} \mathrm{Hg}(28.6 \%)$, and $16.9 \pm 2.4 \mathrm{~mm}$ $\mathrm{Hg}(27.8 \%)$, respectively at the end of the first, second, third, fourth, and fifth year of follow-up (Fig. 2). The mean 


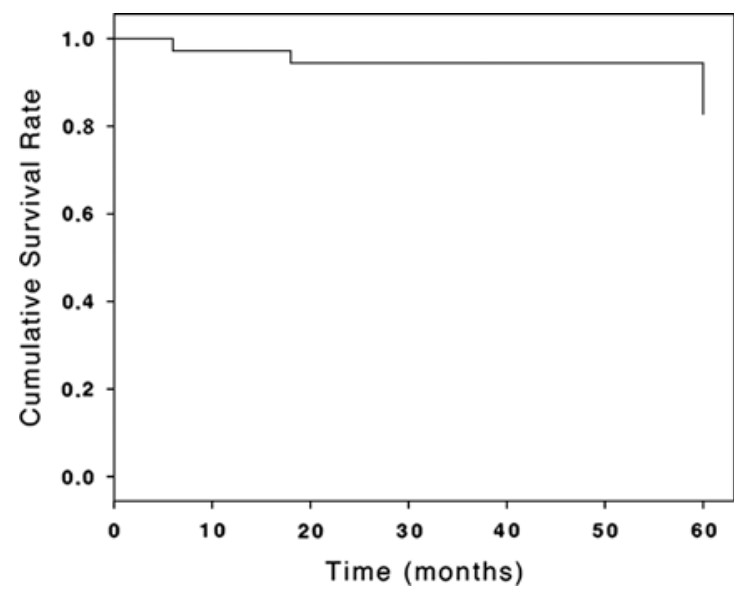

FIGURE 1. Kaplan-Meier survival curve for the study cohort on travoprost monotherapy.

24-hour IOP and calculated AUCs were significantly lower than baseline untreated values at each annual time-point of evaluation $(P<0.01)$, whereas no significant differences were found among yearly time-points during follow-up $(P>0.05)$ (Tables 2, 3).

The mean daytime and nocturnal IOP values at baseline and at each yearly follow-up time-point are shown in Tables 2 and 3. The trend of daytime and nocturnal IOP over time is illustrated in Figure 2. Overall, daytime IOP, nocturnal IOP, and their respective calculated AUCs, were significantly lower than baseline values at each yearly timepoint analyzed $(P<0.01)$. No significant difference was documented for these parameters between yearly timepoints during the 5-year follow-up $(P>0.05)$. No significant differences were detected between nocturnal and diurnal IOP reductions induced by travoprost at each annual time-point analyzed $(P>0.05)$.

Univariate Cox regression analyses revealed no significant effect of age $(P=0.53)$, MD $(P=0.76)$, pattern standard deviation $(P=0.97)$, and treated 24-hour IOP fluctuation $(P=0.53)$ upon the risk of failure during the 5year follow-up period. Only the mean untreated 24-hour IOP and treated 24-hour IOP peak values were found to be risk factors for predicting travoprost treatment failure (HR: 1.9, $P<0.01$ and HR: 1.03, $P<0.01$, respectively) (Table 4).

Treatment-related adverse events during the 5-year course of the study are presented in Table 5. The most common travoprost-related adverse events were iris hyperchromia, seen in 10 patients $(27.7 \%)$ and ocular hyperaemia seen in 3 patients $(8.3 \%)$. No drug-related serious adverse events were registered during the study.

TABLE 1. Characteristics of Studied Patients

\begin{tabular}{lcc}
\hline & \multicolumn{2}{c}{ Patients $(\mathbf{n}=\mathbf{3 6})$} \\
\cline { 2 - 3 } $\begin{array}{l}\text { Sex (Male/Female) } \\
\text { Pseudophakia (n) }\end{array}$ & \multicolumn{2}{c}{$\mathbf{2 0 / 1 6}$} \\
& Mean \pm SD & Range \\
\hline $\begin{array}{l}\text { Age (y) } \\
\text { IOP at enrollment }(10 \mathrm{AM} \pm 1 \mathrm{~h}) \\
\quad(\mathrm{mm} \text { Hg) }\end{array}$ & $24.3 \pm 10.9$ & $52-85$ \\
$\begin{array}{l}\text { Visual field mean deviation at } \\
\text { enrollment }(\mathrm{dB})\end{array}$ & $5.07 \pm 2.15$ & $20-34$ \\
\hline
\end{tabular}

IOP indicates intraocular pressure.

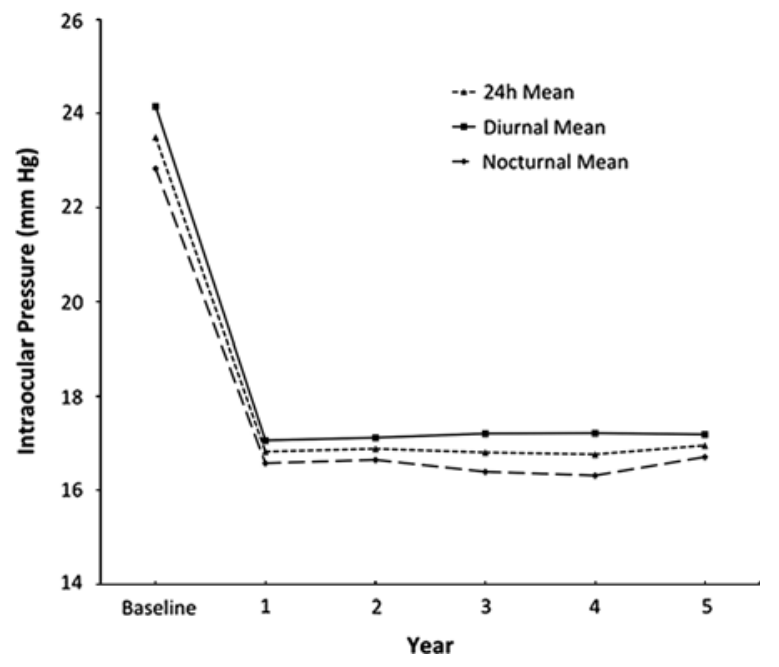

FIGURE 2. The mean 24-hour, diurnal, and nocturnal intraocular pressure at baseline and annual time-points.

\section{DISCUSSION}

Topical therapy for glaucoma should be effective in maintaining a sustained IOP reduction over the long term. ${ }^{21,22}$ Although travoprost monotherapy has shown a meaningful IOP efficacy in the short term, ${ }^{11-16}$ there is limited information on the long-term efficacy $(\geq 12 \mathrm{mo}){ }^{23}$ However, previous clinical trials with latanoprost monotherapy, another prostaglandin analogue, have established a long-lasting daytime hypotensive effect with little evidence of tachyphylaxis, for up to 4 years. ${ }^{24-28}$ This is further corroborated by the present long-term 24-hour study, which documented consistent IOP efficacy with travoprost monotherapy in POAG patients during the 5-year follow-up period.

The present 24-hour investigation observed that a relatively high proportion $(82 \%)$ of POAG patients reached and maintained a predetermined, individualized target IOP reduction between $20 \%$ and $30 \%$ with travoprost monotherapy during a 5-year follow-up period. Similarly, a multicenter study on POAG patients treated with latanoprost monotherapy reported satisfactory IOP control in the vast majority of their patients $(86 \%)$, but this was with a shorter 2-year follow-up. ${ }^{29}$

To the best of our knowledge, this is the first study to monitor the long-term 24-hour IOP efficacy with any medication, or therapy option. Interestingly, the efficacy results of the present long-term 24-hour investigation $(27.8 \%$ to $28.6 \%)$ compare well with the available shortterm evidence for travoprost reported to date. A recent meta-analysis by Stewart et $\mathrm{al}^{1}$ investigating the short-term 24-hour efficacy of topical monotherapy agents reported that travoprost reduced the mean 24 -hour IOP by $27 \%$ from untreated baseline. Further, Konstas et al ${ }^{11,12}$ in 2 separate trials reported travoprost to reduce the mean $24-$ hour IOP by $26.7 \%$ and $26.3 \%$, respectively. In another short-term study by Orzalesi et al, ${ }^{13}$ travoprost reduced the mean 24-hour IOP by $27.4 \%$. The short-term 24-hour efficacy reported by these studies is fairly similar to the long-term 24-hour efficacy documented by the present study. It seems that the long-term 24-hour travoprost efficacy is only slightly greater than that reported over the short-term (with up to 3 mo follow-up). Possible reasons for this small difference include the mechanism of action of 


\begin{tabular}{|c|c|c|c|c|c|c|c|}
\hline & $\begin{array}{c}\text { No. Patients } \\
\text { at Risk }\end{array}$ & 24-h IOP & $\begin{array}{c}P \\
\text { (vs. Baseline) }\end{array}$ & $\begin{array}{l}\text { Daytime } \\
\text { IOP }\end{array}$ & $\begin{array}{c}P \\
\text { (vs. Baseline) }\end{array}$ & $\begin{array}{l}\text { Nocturnal } \\
\text { IOP }\end{array}$ & $\begin{array}{c}P \\
\text { (vs. Baseline) }\end{array}$ \\
\hline Baseline (mm Hg $\pm \mathrm{SD})$ & 36 & $23.4 \pm 1.7$ & & $24.1 \pm 2.0$ & & $22.8 \pm 1.7$ & \\
\hline $12 \mathrm{mo}(\mathrm{mm} \mathrm{Hg} \pm \mathrm{SD})$ & 35 & $16.8 \pm 2.4$ & $<0.01$ & $17.0 \pm 2.8$ & $<0.01$ & $16.5 \pm 2.1$ & $<0.01$ \\
\hline $24 \mathrm{mo}(\mathrm{mm} \mathrm{Hg} \pm \mathrm{SD})$ & 34 & $16.8 \pm 2.5$ & $<0.01$ & $17.1 \pm 2.6$ & $<0.01$ & $16.6 \pm 2.3$ & $<0.01$ \\
\hline $36 \mathrm{mo}(\mathrm{mm} \mathrm{Hg} \pm \mathrm{SD})$ & 34 & $16.8 \pm 2.4$ & $<0.01$ & $17.2 \pm 2.7$ & $<0.01$ & $16.3 \pm 2.2$ & $<0.01$ \\
\hline $48 \mathrm{mo}(\mathrm{mm} \mathrm{Hg} \pm \mathrm{SD})$ & 34 & $16.7 \pm 2.5$ & $<0.01$ & $17.2 \pm 2.7$ & $<0.01$ & $16.3 \pm 2.4$ & $<0.01$ \\
\hline $60 \mathrm{mo}(\mathrm{mm} \mathrm{Hg} \pm \mathrm{SD})$ & 32 & $16.9 \pm 2.4$ & $<0.01$ & $17.1 \pm 2.7$ & $<0.01$ & $16.7 \pm 2.2$ & $<0.01$ \\
\hline$P$ (among yearly time-points) & & 0.71 & & 0.93 & & 0.18 & \\
\hline
\end{tabular}

IOP indicates intraocular pressure.

travoprost, which involves remodeling of the extracellular matrix, ${ }^{30-32}$ hence it is logical to assume a small increase in efficacy after the first few months of treatment.

The mean 24-hour IOP reduction in patients treated with travoprost was generally stable during the 5 years of the study (Fig. 2). It may be of clinical value that the 24-hour efficacy was quite uniform, without significant differences between the yearly 24-hour IOP curves. The long-term consistency of IOP lowering may be important in view of the fact that not all classes of antiglaucoma medications have shown persistence in efficacy over the longterm. For example $\beta$-blockers are reported to demonstrate a long-term drift, probably due to modifications in the number and affinity of continuously blocked $\beta$-adrenergic receptors. ${ }^{33,34}$ Considering the slow, insidious nature of functional and anatomic deterioration in glaucoma, persistence of the hypotensive effect should be considered as an advantage of antiglaucoma therapy.

In previous 24-hour studies with latanoprost, Quaranta et $\mathrm{al}^{35,36}$ observed that although this prostaglandin induced a clinically meaningful 24-hour IOP reduction, the hypotensive effect was greater during the day, especially 8 to 12 hours after administration, albeit these results were not statistically significant. In the meta-analysis performed by Stewart et al, ${ }^{1}$ however, the mean nighttime IOP reduction was statistically lower than the daytime IOP reduction for latanoprost, but not for travoprost. In the present long-term 24-hour study, although mean nocturnal IOP reduction with travoprost was somewhat lower than the mean daytime IOP reduction, there was no significant difference between nighttime and daytime efficacy.

Travoprost was generally well tolerated and no serious drug-related adverse events were recorded throughout this 5-year study. Treatment-related adverse events were observed in 18 patients $(50 \%)$ during the course of the study. These adverse events were consistent with those expected with long-term prostaglandin therapy. Hyperpigmentation of the iris was the most common side effect, with a 5-year cumulative prevalence of $27.7 \%$, which was comparable with the $33.4 \%$ rate reported in a 5-year study with latanoprost. ${ }^{37}$

Importantly, only baseline mean untreated 24-hour IOP and treated 24-hour peak IOP were found to be significant parameters for predicting failure during the 5-year follow-up of the study. As one would expect, the risk of failure due to insufficient IOP lowering increased in those with higher baseline IOP. Thus, in POAG patients with higher untreated mean 24-hour IOP at diagnosis, stepwise therapy may be warranted earlier.

Our study also demonstrated that treated 24-hour peak IOP was a risk factor for travoprost monotherapy failure in POAG. This finding may apply for other prostaglandins and other agents, but this should be confirmed with future studies. It is still controversial whether peak 24hour IOP is an independent risk factor for progression in POAG, or other glaucomas. Further, the role of peak 24hour IOP, or mean 24-hour IOP has not been adequately evaluated in long-term trials to date. The Advanced Glaucoma Intervention Study demonstrated with single IOP measurements over time that a peak IOP $\leq 18 \mathrm{~mm} \mathrm{Hg}$ and a mean IOP of $12.8 \mathrm{~mm} \mathrm{Hg}$ were the best combination to prevent progression in patients with advanced POAG. ${ }^{38}$ Stewart et $\mathrm{al}^{39}$ also reported that peak IOP is an independent risk factor for progression in treated POAG patients followed-up retrospectively for 5 years. Similarly, a 5 -year retrospective study by Hollo et $\mathrm{al}^{40}$ reported that the

TABLE 3. Calculated AUCs for Mean 24-hour, Daytime, and Nighttime IOP at Baseline and During Follow-up

\begin{tabular}{|c|c|c|c|c|c|c|c|}
\hline & $\begin{array}{c}\text { No. Patients } \\
\text { at Risk }\end{array}$ & $\begin{array}{l}\text { AUC for } \\
\text { 24-h IOP }\end{array}$ & $\begin{array}{c}P \\
\text { (vs. Baseline) }\end{array}$ & $\begin{array}{c}\text { AUC for } \\
\text { Daytime IOP }\end{array}$ & $\begin{array}{c}P \\
\text { (vs. Baseline) }\end{array}$ & $\begin{array}{c}\text { AUC for } \\
\text { Nocturnal IOP }\end{array}$ & $\begin{array}{c}P \\
\text { (vs. Baseline) }\end{array}$ \\
\hline Baseline $( \pm$ SD) & 36 & $468.2 \pm 35.3$ & & $194.1 \pm 17$ & & $180.9 \pm 14.9$ & \\
\hline $12 \mathrm{mo}( \pm \mathrm{SD})$ & 35 & $335.5 \pm 49$ & $<0.01$ & $136.5 \pm 23$ & $<0.01$ & $132.3 \pm 17.2$ & $<0.01$ \\
\hline $24 \mathrm{mo}( \pm \mathrm{SD})$ & 34 & $336.7 \pm 49.1$ & $<0.01$ & $137.1 \pm 22$ & $<0.01$ & $133 \pm 18.5$ & $<0.01$ \\
\hline $36 \mathrm{mo}( \pm \mathrm{SD})$ & 34 & $335.3 \pm 48.6$ & $<0.01$ & $138.4 \pm 22.3$ & $<0.01$ & $130.5 \pm 17.5$ & $<0.01$ \\
\hline $48 \mathrm{mo}( \pm \mathrm{SD})$ & 34 & $334 \pm 50.4$ & $<0.01$ & $137.8 \pm 22.5$ & $<0.01$ & $129.9 \pm 18.9$ & $<0.01$ \\
\hline $60 \mathrm{mo}( \pm \mathrm{SD})$ & 32 & $338.3 \pm 48.7$ & $<0.01$ & $138.0 \pm 22.6$ & $<0.01$ & $133.7 \pm 18$ & $<0.01$ \\
\hline$P$ (among yearly time-points) & & 0.71 & & 0.82 & & 0.08 & \\
\hline
\end{tabular}

AUC indicates area under the curve; IOP, intraocular pressure. 


\begin{tabular}{|c|c|c|c|c|c|}
\hline & $\begin{array}{c}\text { Nonfailure } \\
\text { (30 Patients) }\end{array}$ & $\begin{array}{c}\text { Failure } \\
\text { (6 Patients) }\end{array}$ & $\begin{array}{c}P \\
\text { (Nonfailure vs. Failure) }\end{array}$ & $\begin{array}{c}\text { Hazard Ratio } \\
(95 \% \text { CI }) \\
\end{array}$ & $P$ \\
\hline Age & $68.86 \pm 9.5$ & $65.3 \pm 10.9$ & 0.54 & $0.97(0.89-1)$ & 0.53 \\
\hline Mean deviation & $5.06 \pm 2.04$ & $4.84 \pm 2.43$ & 0.75 & $0.94(0.62-1.4)$ & 0.76 \\
\hline Pattern standard deviation & $-3.08 \pm 2.47$ & $-3.07 \pm 1.5$ & 0.48 & $0.99(0.7-1.4)$ & 0.97 \\
\hline Mean 24-h IOP at baseline & $23.15 \pm 1.3$ & $25.19 \pm 2.65$ & $<0.01$ & $1.96(1.23-3.13)$ & $<0.01$ \\
\hline IOP fluctuation & $1.30 \pm 0.22$ & $1.39 \pm 0.19$ & 0.44 & $1.02(0.95-1.1)$ & 0.53 \\
\hline Treated $24 \mathrm{~h}$ IOP peak & $17.83 \pm 1.01$ & $19.4 \pm 0.89$ & $<0.01$ & $1.03(1-1.05)$ & $<0.01$ \\
\hline
\end{tabular}

$95 \% \mathrm{CI}$ indicates $95 \%$ confidence interval; IOP, intraocular pressure.

peak IOP and the mean IOP are independent risk factors for progression in treated exfoliative glaucoma patients. These results are not consistent with other studies investigating the role of peak IOP established with single IOP measurements over a long-term follow-up, in which peak IOP was not found to be an independent risk factor for progression. ${ }^{41-43}$

To date only one previous study ${ }^{44}$ analyzed retrospectively the effect of 24-hour peak IOP on long-term progression in POAG. In that study 24-hour peak IOP was documented to be an independent risk factor for progression, and a 24-hour peak IOP below $18 \mathrm{~mm} \mathrm{Hg}$ ensured a $78 \%$ nonprogression rate in treated POAG patients after 5 years of follow-up. Similarly, in the present prospective study that used travoprost monotherapy, stable patients exhibited a mean treated 24-hour IOP peak of $17.8 \pm$ $1.01 \mathrm{~mm} \mathrm{Hg}$, whereas progressive patients (who were withdrawn from the study) demonstrated a mean treated 24-hour peak IOP of $19.4 \pm 0.89 \mathrm{~mm} \mathrm{Hg}(P<0.01)$.

A limitation of this study is the relatively small sample size. This is due to significant difficulties in enrolling a large cohort of patients with a long follow-up for 24-hour monitoring. Small sample size could have limited the power of statistical analysis, especially regarding the evaluation of parameters as risk factors for failure. Further, progression was evaluated by the principal investigator and relied upon a number of clinical criteria (eg, visual field, optic disc appearance, etc.) and not by a masked observer relying on visual fields, or disc photographs. This approach, however, reflects standard clinical practice used in an academic glaucoma service. Our results apply only to POAG and not to other glaucomas that may be more difficult to control with monotherapy (eg, exfoliative glaucoma, chronic angleclosure glaucoma, etc.). It should also be noted that because our participants had mild POAG, the results might not necessarily apply to patients with more advanced disease whose IOP may be less likely to be controlled with travoprost monotherapy. Another limitation of the study was the incomplete assessor masking: the clinician who performed the IOP measurements knew that the patient was a participant of a long-term travoprost efficacy study

TABLE 5. Adverse Events During the Study Related to Travoprost Therapy

\begin{tabular}{lc}
\hline & $\mathbf{N}(\mathbf{\%})$ \\
\hline Iris hyperpigmentation & $10(27.7)$ \\
Ocular hyperemia & $3(8.3)$ \\
Foreign body sensation & $2(5.5)$ \\
Hypertrichosis & $2(5.5)$ \\
Skin hyperpigmentation & $1(2.7)$ \\
\hline
\end{tabular}

but was masked to the previous baseline or treated IOP data. Although the importance of compliance with medication was stressed to all patients in each visit, no formal method of compliance assessment was used in this study. Such methodology reflects the norm in medium and longterm drug efficacy studies, as well as the real life situation in typical academic glaucoma centers.

Despite these limitations, our long-term study has demonstrated that travoprost monotherapy can consistently control the 24-hour IOP in a significant proportion of POAG patients. Future research is needed to evaluate the long-term 24-hour efficacy of all therapy options in glaucoma. Such evidence may optimize glaucoma care and reduce the rate of glaucomatous visual loss.

\section{REFERENCES}

1. Stewart WC, Konstas AG, Nelson LA, et al. Meta-analysis of 24 hour intraocular pressure studies evaluating the efficacy of glaucoma medicines. Ophthalmology. 2008;115:1117-1122, e1111.

2. Konstas AG, Kozobolis VP, Katsimpris IE, et al. Efficacy and safety of latanoprost versus travoprost in exfoliative glaucoma patients. Ophthalmology. 2007;114:653-657.

3. Yan DB, Battista RA, Haidich AB, et al. Comparison of morning versus evening dosing and 24-h post-dose efficacy of travoprost compared with latanoprost in patients with openangle glaucoma. Curr Med Res Opin. 2008;24:3023-3027.

4. Quaranta L, Katsanos A, Russo A, et al. 24-hour intraocular pressure and ocular perfusion pressure in glaucoma. Surv Ophthalmol. 2013;58:26-41.

5. Aptel F, Cucherat M, Denis P. Efficacy and tolerability of prostaglandin analogs: a meta-analysis of randomized controlled clinical trials. J Glaucoma. 2008;17:667-673.

6. Quaranta L, Biagioli E, Riva I, et al. Prostaglandin analogs and timolol-fixed versus unfixed combinations or monotherapy for open-angle glaucoma: a systematic review and metaanalysis. J Ocul Pharmacol Ther. 2013;29:382-389.

7. Hollo G. The side effects of the prostaglandin analogues. Expert Opin Drug Saf. 2007;6:45-52.

8. Sharif NA, Kelly CR, Crider JY. Agonist activity of bimatoprost, travoprost, latanoprost, unoprostone isopropyl ester and other prostaglandin analogs at the cloned human ciliary body FP prostaglandin receptor. J Ocul Pharmacol Ther. 2002;18:313-324.

9. Sharif NA, Kelly CR, Crider JY. Human trabecular meshwork cell responses induced by bimatoprost, travoprost, unoprostone, and other FP prostaglandin receptor agonist analogues. Invest Ophthalmol Vis Sci. 2003;44:715-721.

10. Aptel F, Denis P. Balancing efficacy and tolerability of prostaglandin analogues and prostaglandin-timolol fixed combinations in primary open-angle glaucoma. Curr Med Res Opin. 2011;27:1949-1958.

11. Konstas AG, Mikropoulos D, Haidich AB, et al. Twenty-fourhour intraocular pressure control with the travoprost/timolol maleate fixed combination compared with travoprost when 
both are dosed in the evening in primary open-angle glaucoma. Br J Ophthalmol. 2009;93:481-485.

12. Konstas AG, Mikropoulos D, Kaltsos K, et al. 24-hour intraocular pressure control obtained with evening- versus morning-dosed travoprost in primary open-angle glaucoma. Ophthalmology. 2006;113:446-450.

13. Orzalesi N, Rossetti L, Bottoli A, et al. Comparison of the effects of latanoprost, travoprost, and bimatoprost on circadian intraocular pressure in patients with glaucoma or ocular hypertension. Ophthalmology. 2006;113:239-246.

14. Przydryga JT, Egloff C. Intraocular pressure lowering efficacy of travoprost. Eur J Ophthalmol. 2004;14:416-422.

15. Franks WA, Renard JP, Cunliffe IA, et al. A 6-week, doublemasked, parallel-group study of the efficacy and safety of travoprost $0.004 \%$ compared with latanoprost $0: 005 \% /$ timolol $0.5 \%$ in patients with primary open-angle glaucoma or ocular hypertension. Clin Ther. 2006;28:332-339.

16. Kumar RS, Istiantoro VW, Hoh ST, et al. Efficacy and safety of a systematic switch from latanoprost to travoprost in patients with glaucoma. J Glaucoma. 2007;16:606-609.

17. Konstas AG, Mikropoulos DG, Irkec M. Open-angle glaucoma and ocular perfusion. Br J Ophthalmol. 2010;94:1273-1274.

18. Hughes E, Spry P, Diamond J. 24-hour monitoring of intraocular pressure in glaucoma management: a retrospective review. J Glaucoma. 2003;12:232-236.

19. Barkana Y, Anis S, Liebmann J, et al. Clinical utility of intraocular pressure monitoring outside of normal office hours in patients with glaucoma. Arch Ophthalmol. 2006;124:793-797.

20. Yildirim N, Sahin A, Gultekin S. The effect of latanoprost, bimatoprost, and travoprost on circadian variation of intraocular pressure in patients with open-angle glaucoma. J Glaucoma. 2008;17:36-39.

21. Friedman DS, Wolfs RC, O'Colmain BJ, et al. Prevalence of open-angle glaucoma among adults in the United States. Arch Ophthalmol. 2004;122:532-538.

22. Leske MC, Wu SY, Honkanen R, et al. Nine-year incidence of open-angle glaucoma in the Barbados Eye Studies. Ophthalmology. 2007;114:1058-1064.

23. Netland PA, Landry T, Sullivan EK, et al. Travoprost compared with latanoprost and timolol in patients with open-angle glaucoma or ocular hypertension. Am J Ophthalmol. 2001;132:472-484.

24. Alm A, Widengard I. Latanoprost: experience of 2-year treatment in Scandinavia. Acta Ophthalmol Scand. 2000;78:71-76.

25. Costagliola C, Del Prete A, Verolino M, et al. Effect of $0.005 \%$ latanoprost once daily on intraocular pressure in glaucomatous patients not adequately controlled by beta-blockers twice daily: a 3-year follow-up. Experience and incidence of side effects in a prospective study on 76 patients. Graefes Arch Clin Exp Ophthalmol. 2002;240:379-386.

26. Watson PG. Latanoprost. Two years' experience of its use in the United Kingdom. Latanoprost Study Group. Ophthalmo$\log y$. 1998;105:82-87.

27. Kashiwagi K, Tsumura T, Tsukahara S. Long-term effects of latanoprost monotherapy on intraocular pressure in Japanese glaucoma patients. J Glaucoma. 2008;17:662-666.

28. Fristrom B, Uusitalo H. A randomized, 36-month, postmarketing efficacy and tolerability study in Sweden and Finland of latanoprost versus non-prostaglandin therapy in patients with glaucoma or ocular hypertension. Acta Ophthalmol. 2010;88:37-43.

29. Hedman K, Watson PG, Alm A. The effect of latanoprost on intraocular pressure during 2 years of treatment. Surv Ophthalmol. 2002;47(suppl 1):S65-S76.

30. Nilsson SF, Drecoll E, Lutjen-Drecoll E, et al. The prostanoid EP2 receptor agonist butaprost increases uveoscleral outflow in the cynomolgus monkey. Invest Ophthalmol Vis Sci. 2006; 47:4042-4049.

31. Weinreb RN, Kashiwagi K, Kashiwagi F, et al. Prostaglandins increase matrix metalloproteinase release from human ciliary smooth muscle cells. Invest Ophthalmol Vis Sci. 1997;38: 2772-2780.

32. Weinreb RN, Toris CB, Gabelt BT, et al. Effects of prostaglandins on the aqueous humor outflow pathways. Surv Ophthalmol. 2002;47(suppl 1):S53-S64.

33. Boger WP III. Shortterm "escape" and longterm "drift." The dissipation effects of the beta adrenergic blocking agents. Surv Ophthalmol. 1983;28(suppl):235-242.

34. Gandolfi SA. Restoring sensitivity to timolol after long-term drift in primary open-angle glaucoma. Invest Ophthalmol Vis Sci. 1990;31:354-358.

35. Quaranta L, Gandolfo F, Turano R, et al. Effects of topical hypotensive drugs on circadian IOP, blood pressure, and calculated diastolic ocular perfusion pressure in patients with glaucoma. Invest Ophthalmol Vis Sci. 2006;47: 2917-2923.

36. Quaranta L, Miglior S, Floriani I, et al. Effects of the timololdorzolamide fixed combination and latanoprost on circadian diastolic ocular perfusion pressure in glaucoma. Invest Ophthalmol Vis Sci. 2008;49:4226-4231.

37. Alm A, Schoenfelder J, McDermott J. A 5-year, multicenter, open-label, safety study of adjunctive latanoprost therapy for glaucoma. Arch Ophthalmol. 2004;122:957-965.

38. The AGIS investigators. The Advanced Glaucoma Intervention Study (AGIS): 7. The relationship between control of intraocular pressure and visual field deterioration. $\mathrm{Am} J$ Ophthalmol. 2000;130:429-440.

39. Stewart WC, Day DG, Jenkins JN, et al. Mean intraocular pressure and progression based on corneal thickness in primary open-angle glaucoma. J Ocul Pharmacol Ther. 2006; 22:26-33.

40. Hollo G, Quaranta L, Cvenkel B, et al. Risk factors associated with progression in exfoliative glaucoma patients. Ophthalmic Res. 2012:47:208-213.

41. Seong GJ, Rho SH, Kim CS, et al. Potential benefit of intraocular pressure reduction in normal-tension glaucoma in South Korea. J Ocul Pharmacol Ther. 2009;25:91-96.

42. Jonas JB, Budde WM, Stroux A, et al. Diurnal intraocular pressure profiles and progression of chronic open-angle glaucoma. Eye (Lond). 2007;21:948-951.

43. Stewart WC, Kolker AE, Sharpe ED, et al. Long-term progression at individual mean intraocular pressure levels in primary open-angle and exfoliative glaucoma. Eur J Ophthalmol. 2008; 18:765-770.

44. Konstas AG, Quaranta L, Mikropoulos DG, et al. Peak intraocular pressure and glaucomatous progression in primary open-angle glaucoma. J Ocul Pharmacol Ther. 2012; 28:26-32. 